\title{
Single-incision robotic adrenalectomy (SIRA): the future of adrenal surgery?
}

\author{
Orhan Agcaoglu, Salih Nafiz Karahan, Tutku Tufekci, Serdar Tezelman \\ Department of General Surgery, School of Medicine, Koc University, Istanbul, Turkey \\ Contributions: (I) Conception and design: O Agcaoglu; (II) Administrative support: O Agcaoglu, S Tezelman; (III) Provision of study materials \\ or patients: O Agcaoglu; (IV) Collection and assembly of data: SN Karahan, T Tufekci; (V) Data analysis and interpretation: O Agcaoglu; (VI) \\ Manuscript writing: All authors; (VII) Final approval of manuscript: All authors. \\ Correspondence to: Orhan Agcaoglu. Koc University, Davutpasa Cad. No:4 Topkapi, Istanbul, Turkey. Email: oagcaoglu@gmail.com.
}

\begin{abstract}
In compliance with the trend toward less invasive techniques, single incision robotic surgeries have become more common and they have been increasingly used for several surgeries including adrenalectomy. Single incision robotic adrenalectomy (SIRA) aims to combine the merits of robotic surgery with previously defined single incision laparoscopic techniques. It has been shown to be safe and feasible, however, there are only few studies on this new technique. Due to scant data on SIRA in the current literature, it remains to be a current challenge in adrenal surgery. In this review, our goal is to present current literature on SIRA and discuss the data regarding perioperative outcomes, patient selection, learning curve, and its limitations.
\end{abstract}

Keywords: Adrenal tumor; minimally invasive surgery; robotic adrenalectomy; single-incision robotic surgery; single-port robotic surgery

Submitted Nov 22, 2019. Accepted for publication Apr 02, 2020.

doi: $10.21037 /$ gs-2019-ra-02

View this article at: http://dx.doi.org/10.21037/gs-2019-ra-02

\section{Introduction}

To date, adrenalectomy is the preferred method of treatment in a clear majority of patients with adrenal tumor. While historically open procedures were preferred, nowadays there are multiple minimally invasive options for adrenal gland surgery. After the first ever laparoscopic adrenalectomy in 1992, it has become the gold standard in the removal of adrenal tumors including hormone secreting adrenal tumors, large tumors with a suspicion for malignancy and isolated adrenal metastasis $(1,2)$. Despite providing advantages including decreased the length of hospital stay, reduced postoperative pain and better cosmetic outcomes, laparoscopic surgery does not significantly overcome the cons of conventional technique yet $(3,4)$. These drawbacks along with advancements in robotic and laparoscopic equipment lead to development of less invasive and possibly better techniques. After reaching a threshold of learning curve and experience, most surgeons seek for new techniques that are less invasive with better perioperative outcomes (5) such as laparoendoscopic single site surgery (LESS) and natural orifice transluminal endoscopic surgery (NOTES).

According to the current literature, the use of LESS and NOTES in adrenalectomy has already been proven to be safe and feasible $(6,7)$. Despite having no significant advantage in terms of blood loss and complications when compared to conventional multiport surgery $(8,9)$ LESS enables better cosmetic appearance (9-12) and reduced postoperative pain $(8,9)$. On the other hand, technical disadvantages including instrument clashing, suboptimal ergonomics and lack of instrument triangulation (13) drove the surgeons to search for better techniques and instrumentations.

Robotics have gained popularity during the last decades due to its advantages over laparoscopy such as $3 \mathrm{D}$ enhanced vision, articulated instrumentation, decreased tremor with improved dexterity and better surgeon comfort. Since the first robotic adrenalectomy was performed in 1999 (14), endocrine surgeons have increasingly utilized robots for 
adrenal surgery.

As the patients and surgeons desire more minimally invasive techniques, single incision robotic surgery became popular in recent years. The first single incision robotic surgery was performed in 2009 for prostatectomy by White et al. (15). From 2009 on, it has been widely used by many surgical specialties for hysterectomy, prostatectomy, colectomy and nephrectomy. Although in general surgery it is most commonly performed for cholecystectomy, single incision robotic adrenalectomy (SIRA) has also been getting popular day by day. It remains to be a current challenge in adrenal surgery, after it was done by Park et al. for the first time in 2011 using da Vinci robotic system (Intuitive surgical, Inc., Sunnyvale, CA, USA) (16). Although it has been 8 years, past, there is still scant data and debates about SIRA. Despite previously shown to be safe and feasible $(13,17)$, lack of quality data from randomized controlled trials and prospective studies causes debate on oncologic results, cosmetic appearance and postoperative pain after SIRA. Our aim is to present and review the properties of SIRA including perioperative results, patient selection, learning curve, cost-effectiveness and its limitations as well as newly emerging single incision technologies in this review.

\section{Patient selection}

Appropriate patient selection is crucial when performing a new technique due to the surgeon's lack of experience and early steps in the learning curve. During this period, wrong patient selection may lead to increased complications masking real outcomes. Due to absence of adequate data, there is still a controversy and no consensus on patient selection criteria for SIRA. Regarding this, Park et al. (18) suggest that surgeons who are performing SIRA at the beginning of their learning curve should avoid advanced cases such as obese patients (BMI >30) with large tumors $(>2 \mathrm{~cm})$ in addition to patients with proven malignant tumors. Due to the fact that this study (18) only evaluated the results of posterior retroperitoneal approach, their results might not be valid for lateral transabdominal surgery. On the other hand, in another study Lee et al. (17) claimed that SIRA is safe and feasible for patients with functioning and nonfunctioning tumors regardless of their BMI.

Different approaches like lateral transabdominal adrenalectomy and posterior retroperitoneal adrenalectomy also exist for SIRA, however, data comparing their results is still limited. Recently, Kan et al. (19) compared them subjectively in a case based manner as they presented 2 cases with transabdominal and 1 case with posterior retroperitoneal approach. The authors claim that blood loss and operative time are similar in both approaches. While transabdominal approach enables easier orientation and localization of the tumor, this study they noted retroperitoneal approach would be more useful especially in obese patients, patients with enlarged liver and with a history of previous abdominal surgery (19).

Considering limited number of studies on SIRA, data from other specialties and techniques may show pros and cons of single incision robotic surgery. According to the results of a study on single incision robotic colectomy (SIRC) by Juo et al. (20) incisional hernia and conversion to open surgery was reported to be more common in patients with $\mathrm{BMI}>30$, which lead the authors to change their selection criteria and operate only on patients with $\mathrm{BMI}<30$.

\section{Perioperative outcomes}

Perioperative outcomes such as estimated blood loss, operative time and conversion to multiport laparoscopic or open technique are important for the evaluation of SIRA. Regarding these outcomes, there is scarce data in the literature limited to case reports and small cohorts only. In a recent matched cohort study comparing 16 single port robotic assisted adrenalectomies with 16 laparoscopic adrenalectomies by Arghami et al. (13) it has been shown that both techniques have similar outcomes regarding operative time $(183 \pm 33$ vs. $170 \pm 40$ mins, $\mathrm{P}=0.63)$ and estimated blood loss $(576 \pm 377$ vs. $618 \pm 372 \mathrm{~mL}, \mathrm{P}=0.68)$. The authors also noted the superiority of SIRA in terms of shorter hospital stay and blood loss, however, these results were not statistically significant $(\mathrm{P}=0.23)$ (13). The conversion rate was comparable in both groups being only $6 \%$ (13). Moreover, an important result of this study was the approximately $50 \%$ less narcotic analgesic requirement in SIRA group compared to the gold standard multiport laparoscopic surgery $(\mathrm{P}<0.001)$ (13). Furthermore, Lee et al. (17) investigated 33 patients and presented similar perioperative outcomes including operative time and length of hospital stay. In this study, the conversion rate was reported as $13 \%(17)$.

Thus, when we analyze the outcomes of single incision laparoscopic adrenal surgery, there are various studies comparing SILS and multiport laparoscopic adrenalectomy. Although the initial studies showed longer operative times 
for SILS groups, the recent studies which are generally performed by more experienced surgeons who have already reached their learning curves noted similar perioperative outcomes especially in terms of operative time and blood loss (6). Moreover, studies comparing both techniques noted no difference in terms of hospital stay $(5,6)$. There is one recent meta-analysis with 704 patients in total, revealed no significant difference in operative time between study groups (5). On the other hand, Agcaoglu et al. (6) reported a significantly increased operative time in overweight patients. This can be very important especially in the selection of appropriate technique in this particular patient group. Taking these articles into account, we can at least say that decreasing number of incisions or ports does not worsen perioperative outcomes such as operative time, conversion rate and bleeding while decreasing the need of narcotics and enabling better cosmesis. In order to validate more promising results, the current literature is inadequate and new prospective randomized multicentric studies including larger patient groups are needed.

\section{Learning curve}

Learning curve is defined as the number of operations required for a surgeon to reach to a level at which the surgical results are not inferior to the gold standard technique. Learning curve is important because it has been known to directly affecting operative time, estimated blood loss, conversion rates and postoperative complications. Already having been shown in the literature, many surgeons noticed decreased operative time as they increase their experience in the technique. In laparoscopic adrenal series, this learning curve ranges from 10 to 30 cases. In spite of the fact that there is ongoing disagreement for exactly how many operations are needed to reach a threshold in conventional robotic adrenalectomy, the learning curve is steep even for a surgeon with an experience in laparoscopic surgery (21).

In the literature, the minimum number of operations required for reaching the cutoff point of the learning curve for multiport robotic adrenalectomy is reported approximately as 20 patients (22-24). There is only one study reporting the learning curve of SIRA which states a cutoff of 21 operations (17). This is comparable to conventional robotic multiport adrenalectomy (20) procedures. In this study, the difference in mean operative time between the first 7 cases and 7 cases after passing threshold was 21 minutes (17). There was also another important point that we should highlight. These studies have been performed by senior surgeons and tertiary centers, which might cause them to underpredict the real number of cases needed to overcome the learning curve.

Even though adaptation to SILS is challenging and someone needs previous surgical expertise in multiport laparoscopy, we believe that this will be different for robotic system. In both robotic multiport and single incision techniques, the surgeon performs the same movement from the master slave console of the robotic system. Moreover, the new robotic model of Intuitive Surgery, Da Vinci Sp (Intuitive surgical, Inc., Sunnyvale, CA, USA) has more ergonomic design with a sing port preventing clashing of instruments while still allowing the same precise dissection with articulated instrumentation. Therefore, we think that the learning curve will not be as steep as SILS adrenalectomy.

\section{Partial adrenalectomy (cortex sparing surgery)}

Recently, organ preserving surgeries requiring finer work are becoming more popular. One of them is partial adrenalectomy, in which a part of adrenal cortex is spared to conserve adrenal function and eliminate the need for life long steroid replacement. Since robotic partial adrenalectomy was done by St Julien et al. (25) for the first time in 2006, numerous studies have proven its feasibility (26-28). Partial adrenalectomy offers comparable perioperative outcomes, complications and surgical outcome to the total removal of adrenal gland (29).

The success of this operation depends on complete exposure of the tumor, negative margins, full inspection of the gland for additional possible tumors and bleeding control (30). We believe that the properties of robotic system would improve the ability of the surgeon to do precise dissection which may help the surgeon to achieve better outcomes after partial adrenalectomy.

To date, as far we know there is no cohort studies regarding the use of SIRA in partial adrenalectomy. Thus, we may only estimate its efficacy by utilizing its similarity to SILS adrenal series. In one of these studies, Ho et al. (30) reported on 11 patients and noted the feasibility and safety of SILS partial adrenalectomy. We can estimate that due to the proven successful results of multiport robotic system and SILS partial adrenalectomy, the results of SIRA would be composed of advantages of these two techniques ending in superior operative outcomes.

\section{Cost}


High cost is considered as the major disadvantage of robotic surgery in general. Because of expensive initial price of the robot, costly maintenance and expensive instruments, use of robot instead of laparoscopy costs around additional $\$ 1,000$ (31,32). Several studies found out that it is valid also robotic adrenalectomy. According to Winter et al. (33) a patient undergoing robotic adrenalectomy are charged significantly more than those undergoing laparoscopic adrenalectomy. In contrast, according to Feng et al. (34) there is no statistically significant difference between costs of robotic and laparoscopic adrenalectomy. In this study, authors claimed that if the instrument usage is temperate and excessive usage is avoided, the cost may be significantly reduced (34). In addition, various authors reported that it is possible for high volume centers to decrease the costs of robotic surgeries $(33,35)$.

As the current literature lacks data on SIRA, there is only one study reporting the cost of SIRA, which shows a $16 \%$ reduced price compared multiport laparoscopic adrenalectomy although the difference is not statistically significant. In this study, the authors mentioned the cause of reduced cost as shorter hospital stay after undergoing SIRA and decreased need for narcotic use (13).

\section{Rationale for SIRA}

Trocar related complications play an important clinical role in laparoscopic procedures and are seen in $0.1-10 \%$ of cases (36). These complications are categorized into 2 groups as those happening upon trocar insertion and those happening after removal in the postoperative period. Those occurring upon initial trocar placement include injuries to major vessels or visceral organs as well as some other minor injuries. Complications occurring after trocar removal includes incisional hernias, bleedings and surgical site infections $(37,38)$. As indicated in the literature, postoperative trocar related complications depend on operative time and size of the trocar (37). Decreasing one or both hypothetically would decrease these complications. On the other hand, by avoiding multiple trocars single port surgeries aim to decrease trocar related complications, trocar related pain and improve cosmetic results (39).

Although several authors reported no significant difference in operative time in single incision surgeries, Juo et al. (20) found increased rates of surgical site infections and incisional hernia when they compared outcomes of single incision robotic colectomy with laparoscopic colectomy.

\section{Technical innovations}

Until 2019, all robotic models including Da Vinci S, Si, $\mathrm{X}$, Xi had multiple surgical arms similar to laparoscopic surgery. Approved in 2018 by FDA and introduced to the market in 2019, Da Vinci Single Port (Sp) system has only one arm passing through a single $2.5 \mathrm{~cm}$ trocar containing the flexible camera and 3 articulated working arms. It has been reported to be used for nephrectomy, cystectomy and prostatectomy (40-42) in the past, however there are no cases of adrenalectomy, there is no report regarding $\mathrm{Da}$ Vinci Sp use in adrenalectomy.

\section{Conclusion}

Single incision robotic adrenalectomy is safe and feasible and can be used more commonly with the development of Da Vinci Sp (Intuitive surgical, Inc., Sunnyvale, CA, USA). However, as the studies about SIRA in the literature are scarce, the pros and cons of this technique have not been established effectively. Therefore, there is still a strong need for prospective studies with higher number of patients to generate more reliable data.

\section{Acknowledgments}

Funding: None.

\section{Footnote}

Provenance and Peer Review: This article was commissioned by the Guest Editor (Özer Makay) for the series "Robotic Adrenalectomy" published in Gland Surgery. The article was sent for external peer review organized by the Guest Editor and the editorial office.

Conflicts of Interest: All authors have completed the ICMJE uniform disclosure form (available at http:// dx.doi.org/10.21037/gs-2019-ra-02). The series "Robotic Adrenalectomy" was commissioned by the editorial office without any funding or sponsorship. The authors have no other conflicts of interest to declare.

Ethical Statement: The authors are accountable for all aspects of the work in ensuring that questions related to the accuracy or integrity of any part of the work are appropriately investigated and resolved. 
Open Access Statement: This is an Open Access article distributed in accordance with the Creative Commons Attribution-NonCommercial-NoDerivs 4.0 International License (CC BY-NC-ND 4.0), which permits the noncommercial replication and distribution of the article with the strict proviso that no changes or edits are made and the original work is properly cited (including links to both the formal publication through the relevant DOI and the license). See: https://creativecommons.org/licenses/by-nc-nd/4.0/.

\section{References}

1. Gagner M, Lacroix A, Bolte E. Laparoscopic adrenalectomy in Cushing's syndrome and pheochromocytoma. N Engl J Med 1992;327:1033.

2. Hupe MC, Imkamp F, Merseburger AS. Minimally invasive approaches to adrenal tumors: an up-to-date summary including patient position and port placement of laparoscopic, retroperitoneoscopic, robot-assisted, and single-site adrenalectomy. Curr Opin Urol 2017;27:56-61.

3. Marcovici I. Significant abdominal wall hematoma from an umbilical port insertion. Jsls 2001;5:293-5.

4. Lowry PS, Moon TD, D'Alessandro A, et al. Symptomatic port-site hernia associated with a non-bladed trocar after laparoscopic live-donor nephrectomy. J Endourol 2003;17:493-4.

5. Wu S, Lai H, Zhao J, et al. Laparoendoscopic Singlesite Adrenalectomy versus Conventional Laparoscopic Adrenalectomy: An Updated Meta Analysis. Urol J 2016;13:2590-8.

6. Agcaoglu O, Sengun B, Senol K, et al. Comparison of Technical Details and Short-term Outcomes of Singleincision Versus Multiport Laparoscopic Adrenalectomy. Surg Laparosc Endosc Percutan Tech 2019;29:49-52.

7. Wang L, Wu Z, Li M, et al. Laparoendoscopic single-site adrenalectomy versus conventional laparoscopic surgery: a systematic review and meta-analysis of observational studies. J Endourol 2013;27:743-50.

8. Horstmann M, Kugler M, Anastasiadis AG, et al. Laparoscopic radical cystectomy: initial experience using the single-incision triangulated umbilical surgery (SITUS) technique. World J Urol 2012;30:619-24.

9. Castellucci SA, Curcillo PG, Ginsberg PC, et al. Single port access adrenalectomy. J Endourol 2008;22:1573-6.

10. Cuesta MA, Berends F, Veenhof AA. The "invisible cholecystectomy": A transumbilical laparoscopic operation without a scar. Surg Endosc 2008;22:1211-3.

11. Vidal O, Valentini M, Espert JJ, et al. Laparoendoscopic single-site cholecystectomy: a safe and reproducible alternative. J Laparoendosc Adv Surg Tech A 2009;19:599-602.

12. Han WK, Park YH, Jeon HG, et al. The feasibility of laparoendoscopic single-site nephrectomy: initial experience using home-made single-port device. Urology 2010;76:862-5.

13. Arghami A, Dy BM, Bingener J, et al. Single-port roboticassisted adrenalectomy: feasibility, safety, and costeffectiveness. JSLS 2015;19:e2014 00218.

14. Piazza L, Caragliano P, Scardilli M, et al. Laparoscopic robot-assisted right adrenalectomy and left ovariectomy (case reports). Chir Ital 1999;51:465-6.

15. White MA, Haber GP, Autorino R, et al. Robotic laparoendoscopic single-site radical prostatectomy: technique and early outcomes. Eur Urol 2010;58:544-50.

16. Park JH, Walz MK, Kang SW, et al. Robot-assisted posterior retroperitoneoscopic adrenalectomy: single port access. J Korean Surg Soc 2011;81 Suppl 1:S21-4.

17. Lee GS, Arghami A, Dy BM, et al. Robotic single-site adrenalectomy. Surg Endosc 2016;30:3351-6.

18. Park JH, Kim SY, Lee CR, et al. Robot-assisted posterior retroperitoneoscopic adrenalectomy using single-port access: technical feasibility and preliminary results. Ann Surg Oncol 2013;20:2741-5.

19. Kan HC, Pang ST, Wu CT, et al. Robot-assisted laparoendoscopic single site adrenalectomy: A comparison of 3 different port platforms with 3 case reports. Medicine (Baltimore) 2017;96:e9479.

20. Juo YY, Luka S, Obias V. Single-incision robotic colectomy (SIRC): Current status and future directions. J Surg Oncol 2015;112:321-5.

21. Morris LF, Perrier ND. Advances in robotic adrenalectomy. Curr Opin Oncol 2012;24:1-6.

22. Rosoff JS, Otto BJ, Del Pizzo JJ. The emerging role of robotics in adrenal surgery. Curr Urol Rep 2010;11:38-43.

23. Giulianotti PC, Buchs NC, Addeo P, et al. Robot-assisted adrenalectomy: a technical option for the surgeon? Int J Med Robot 2011;7:27-32.

24. Brunaud L, Bresler L, Ayav A, et al. Robotic-assisted adrenalectomy: what advantages compared to lateral transperitoneal laparoscopic adrenalectomy? Am J Surg 2008;195:433-8.

25. St Julien J, Ball D, Schulick R. Robot-assisted corticalsparing adrenalectomy in a patient with Von HippelLindau disease and bilateral pheochromocytomas separated by 9 years. J Laparoendosc Adv Surg Tech A 2006;16:473-7. 
26. Boris RS, Gupta G, Linehan WM, et al. Robot-assisted laparoscopic partial adrenalectomy: initial experience. Urology 2011;77:775-80.

27. Asher KP, Gupta GN, Boris RS, et al. Robot-assisted laparoscopic partial adrenalectomy for pheochromocytoma: the National Cancer Institute technique. Eur Urol 2011;60:118-24.

28. Gupta NP, Nayyar R, Singh P, et al. Robot-assisted adrenal-sparing surgery for pheochromocytoma: initial experience. J Endourol 2010;24:981-5.

29. Kaye DR, Storey BB, Pacak K, et al. Partial adrenalectomy: underused first line therapy for small adrenal tumors. J Urol 2010;184:18-25.

30. Ho CH, Liao PW, Lin VC, et al. Laparoendoscopic single-site (LESS) retroperitoneal partial adrenalectomy using a custom-made single-access platform and standard laparoscopic instruments: technical considerations and surgical outcomes. Asian J Surg 2015;38:6-12.

31. Aliyev S, Karabulut K, Agcaoglu O, et al. Robotic versus laparoscopic adrenalectomy for pheochromocytoma. Ann Surg Oncol 2013;20:4190-4.

32. Pineda-Solís K, Medina-Franco H, Heslin MJ. Robotic versus laparoscopic adrenalectomy: a comparative study in a high-volume center. Surg Endosc 2013;27:599-602.

33. Winter JM, Talamini MA, Stanfield CL, et al. Thirty robotic adrenalectomies: a single institution's experience. Surg Endosc 2006;20:119-24.

34. Feng Z, Feng MP, Levine JW, et al. Robotic retroperitoneoscopic adrenalectomy: useful modifications

Cite this article as: Agcaoglu O, Karahan SN, Tufekci T, Tezelman S. Single-incision robotic adrenalectomy (SIRA): the future of adrenal surgery? Gland Surg 2020;9(3):853-858. doi: 10.21037/gs-2019-ra-02 of the described posterior approach. J Robot Surg 2017;11:409-14.

35. Feng Z, Feng MP, Feng DP, et al. A cost-conscious approach to robotic adrenalectomy. J Robot Surg 2018;12:607-11.

36. Vilos GA, Vilos AG, Abu-Rafea B, et al. Three simple steps during closed laparoscopic entry may minimize major injuries. Surg Endosc 2009;23:758-64.

37. Swank HA, Mulder IM, la Chapelle CF, et al. Systematic review of trocar-site hernia. Br J Surg 2012;99:315-23.

38. Juo YY, Hyder O, Haider AH, et al. Is minimally invasive colon resection better than traditional approaches?: First comprehensive national examination with propensity score matching. JAMA Surg 2014;149:177-84.

39. Kim SJ, Choi BJ, Lee SC. Overview of single-port laparoscopic surgery for colorectal cancers: past, present, and the future. World J Gastroenterol 2014;20:997-1004.

40. Kaouk J, Garisto J, Bertolo R. Robotic Urologic Surgical Interventions Performed with the Single Port Dedicated Platform: First Clinical Investigation. Eur Urol 2019;75:684-91.

41. Kaouk J, Bertolo R, Eltemamy M, et al. Single-Port Robot-Assisted Radical Prostatectomy: First Clinical Experience Using The SP Surgical System. Urology 2019;124:309.

42. Dobbs RW, Halgrimson WR, Madueke I, et al. Singleport robot-assisted laparoscopic radical prostatectomy: initial experience and technique with the da Vinci((R)) SP platform. BJU Int 2019;124:1022-7. 